\title{
Sustainable Geometric and Bio-Cultural/Cultural Models of Human Society: The Role of Non-Capitalist Cooperation in Times of Civilizational/Environmental Crisis
}

\author{
M. S. Sthel ${ }^{1}$, J. G. R. Tostes ${ }^{1} \&$ J. R. Tavares ${ }^{2}$ \\ ${ }^{1}$ Center of Science and Technology, North Fluminense State University, Campos dos Goytacazes, Brazil \\ ${ }^{2}$ Coordination of Natural Sciences and Mathematics, Federal Institute of Education, Science \& Technology, \\ Campos dos Goytacazes, Brazil \\ Correspondence: M. S. Sthel, Center of Science and Technology, North Fluminense State University, Campos \\ dos Goytacazes, Brazil. E-mail: sthel@uenf.br
}

Received: September 10, 2016

doi:10.5539/jsd.v10n2p13
Accepted: November 10, 2016

Online Published: March 30, 2017

URL: https://doi.org/10.5539/jsd.v10n2p13

\begin{abstract}
The Sustainable Complex Triangular Cells (SCTC) and bio-cultural/cultural models of human society are employed here. Regarding SCTC model, the cell areas represent the individual's carbon footprint. Scalene triangles represent each individual in the present competitive standard (inward arrows). Equilateral triangles (outward arrows) are "summed" so as forming cooperative-hexagonal bodies leading to a collaborative model of society, reducing the total carbon footprint area as regard the formal analogous sum of each individual (inward) non-cooperative triangle. We particularly have focused on environmental global limits of the capitalist system, with SCTC modeling an accelerated global anti-ecological "scalenization" process from the 29 crisis to the present neoliberal stage of capitalism. Employing again the SCTC model, we describe and exemplify instable and short lifetime "islands" built up through evanescent local process of "cooperative equilateralization" (outward arrows) in the last 40 years. Such non-capitalist features were "mixed in" with competitive "scalenized" features of the capitalist "ocean". In the final topic, we will consider bio-cultural (Nowak and Wilson) models of the human history and a cultural (Weber-Alberoni) model for great inflexions in the western history. All these models intersect via human cooperation. Particularly, that last model is complementary to the above small and instable "islands" sketch: but now we deal with western religious and secular, non- capitalist, purely cooperative experiences, which correspond to the above labeled SCTC "cooperative equilateralization". Such weber-alberonian "islands" may be - some few times - sufficiently stable for rapid and great expansions leading, e.g., to a "civilizational/environmental jump" in the presently menaced planet.
\end{abstract}

Keywords: triangular cells, competition, cooperation, system science, climate changes, economic system, environmental limits of capitalism, bio-cultural and cultural models of society

\section{Introduction}

We are opening this work briefly displaying a background western civilization pattern and its relationships with the process of growing global environmental problems. Now for the first time along the history of civilizations we are really facing global civilization challenges. Putting aside, for the sake of simplification, the classical antiquity and the middle Ages, the modern stage of the western civilization, that would lead Europe to a world political-economic hegemony, was triggered around the beginning of XVI century. At the "material" side of history, there happened a monumental change of oceanic basin, from the "small" Mediterranean "ocean" to the immense Atlantic Ocean, that has turbinated the nascent capitalism. At the "immaterial" side (ideas, beliefs and values) - articulated with that material side changes - there happened a profound inflexion in the western reason: the modern science was born, centered in a "scientific method" and in the XVII century Cartesian man-nature separation. This material and immaterial process would lead, in the XVIII Century, to the European Enlightenment civilization project. Since the XIX Century, that project has leveraged a planetary industrial economic system that has generated a huge technological development, great waves of unemployment and inequality and gigantic economic crises. Such crises (particularly 1929 and 2008 crises), in turn, have also helped promoting a gigantic environmental crisis (which in turn reacts back on the economic sphere), 
particularly highlighting today global warming effects. Such a non-ecological trajectory of articulated contradictions seems to be pushing the very competitive world economic system to its ultimate limits. Here, once again, it is happening - from the material side of history - a new monumental change of oceanic basin. From the Atlantic basin (sphere of geopolitical hegemony of USA and EU) to the Pacific basin (new sphere of geopolitical hegemony of USA and China) that change may also push capitalism to its ultimate limits, since, as the Earth is round, the world reserves of inexpensive work are coming to an end. And once again - from the immaterial side of history and articulated with that material side change - it is in course a conflict of an old scientific thinking (the Newton-Cartesian thinking) and a new scientific thinking (the systemic thinking). Several concepts of this paragraph will be found distributed and explained along the present work.

The twenty-first century begins with a challenge to the civilization process: the environment. The amazing material progress achieved by the human society by intensive use of technology and the huge expansion of the capitalist system would have a limit? Facing a possible shortage of natural resources due to the increasing consumption of material goods, with life cycles becoming smaller, how can one indefinitely sustain this model of society? The application of neoliberal policies (Andrews et al., 2013; Klitgaard, 2013; Pellizzoni, 2011; Heath and Gifford, 2006) from the mid-1980s advocated an increasingly competitive, consumer and individualistic society, generating an overwhelming increase in energy consumption and a big boot as regard the sources of planet natural resources.

From the Industrial Revolution, the era of fossil fuels was highly intensified in the twentieth century with the expansion of industries and intense urbanization. In 2007, the Intergovernmental Panel on Climate Change (IPCC, 1007) published an alarming report, indicating that climate change would be caused by large-scale use of fossil fuels, which was causing an increase in greenhouse gas emissions, thus intensifying global warming and producing the fearful climate change (Randerson, 2013; Stocker, 2013; Cox et al., 2013; Hansen et al., 2012; Solomon et al., 2009; Rockstrom et al., 2009).

Environmental impacts of major proportions are being expected, which will directly affect human society and biodiversity (Flynn et al., 2012; Palmer, 2014; Ding et al., 2014; Balmaseda et al., 2013; Ramsay, 2014; Lenoir et al., 2008; Rosenzwieg, 2008). Therefore, we have a great challenge: the pursuit of a low carbon economy. During 2006 and 2007, with the release of the N. Stern (2006) and the IPCC reports, it seemed that the environmental problems would finally be part of governmental international agendas and of the real concerns of the economic system. However, since 2008, a shift of priorities for the issues associated to the economic crisis has been conducted, sensibly reducing the space for discussion of important issues such as climate change. During the United Nations Climate Change Conference in Doha, Qatar, advances were largely incipient, including the postponement, to after 2015, of urgent measures for reducing greenhouse gas emissions. Now, there are reasonably well founded expectations on good news about such reductions in the Paris 21th COP (Tollefson J. \& Weiss K, 2015)

Rockstrom (2009) points more eight great environmental global problems. Worst, these nine problems are interconnected and may reinforce each other. So, this set of problems is responsible, in a large extent, for what it is known today as a "global environmental crisis".

We are witnessing today a serious and complex conflict between man and nature (Prigogine, 1984; Prigogine and Stengers, 1984), where the dominant view of the current economic model was responsible for transforming human society into a market where the main objective is to encourage individualism and competition, using as a premise "the invisible hand of the market" that would solve all the economy problems. This old view was challenged starting from the 2008 severe economic crisis, where other premise was observed: "the visible hand of the state", where huge sums of public money (many individuals) were used to save the market society (few individuals). During this crisis, many efforts and work of a lot of people, traduced in taxes, have been used to save very small amount of people (the financial system), in order to prevent, as it was said, "large instabilities in the global economic system". To deal with that gigantic current crisis, the environment soon lost its alleged and evanescent 2006-2007 priority; this is very worrying, especially with regard to major environmental impacts predicted to the global climate change. The alleged priority, particularly since 2008 crisis, is to facing the economic crisis. The present work envisages the scenario of those both (environmental and economic) two crisis as two unavoidably articulated and feedback aspects pointing to severe limits of the own ongoing capitalist civilization project.

In this work, an analysis of the current context of the civilization process was performed and the conflict between man and nature has become the core of environmental issues. Topic 2: In 2012, Sthel and Tostes proposed a sustainable triangular model of complex cells (SCTC) (Sthel and Tostes, 2012) that was used in order 
to facilitate the understanding of that complex conflict. This proposed triangle has three unavoidably tied vertices: Economy, Environment and Energy (EEE triangle). The figure of a scalene triangle with arrows pointed at its center is the individual accumulation of consumption goods. The area of the triangle is the footprint of any human, individualized, competitive and voracious consumer of natural resources. On the other side, the figure of an equilateral triangle with arrows pointing outwards is employed to symbolize a strong cooperation and interaction between individuals and, finally, a regular hexagon can be constructed "summing" six of those triangles to symbolize the sharing of natural resources in order to reduce individual's carbon footprint (reducing the total area of the hexagon).

The model also incorporates the idea of the inseparability of concepts (energy, economy, and environment) that are located at the vertices of the triangle, symbolizing that the current energy consumption, environmental and economic crises have no separate solutions (Sthel et al., 2013). The SCTC model can be used in order to reduce the energy footprint for the scenario of 2030 (Sthel et al., 2013), based on the proposal of Chakravarti et al. (2009).

Before starting to dealing with the purposes of the present work in the topic 3, it has been carried out a quick and unconventional background analysis of the general limits of capitalism through capitalist authors, pos-2008 crisis.

Then, specially focusing - in topic 3 - the environmental global limits of capitalism and starting to apply our SCTC geometric model we - schematically - stress that it is in course an expansive and accelerated "scalenization" global process of the economic system from the 29 crisis to the present neoliberal capitalist stage. It will be given emphasis to the present stage of that "scalenization" process and, additionally, to only one side (tying the vertexes Economy and Environment) of the scalene triangle representing each individual. This is the "geometric" process of contradictory articulation between the hegemonic vertex of Economy (present global capitalism) and the vertex of Environment (emphasis in those limits of capitalism put by the present global environmental crisis).

Remaining in the topic 3 and again applying our SCTC model: along the last 45 years - during which environmental crisis emerged in the public and governmental sphere - some local, unstable and evanescent experiences of cooperative "equilateralization" (arrows out), aiming at sustainability results, occurred. Usually, such non-capitalist cooperative "equilateralization" "islands" appeared - right from the start - mixed, to some extent and contradictorily, with capitalist competitive "scalenization" "ocean" (Sachs, 1991; Sachs, 2009; Ostrom, 2009). A process that drives, usually, to "island" short lifetimes.

Coming to the next and final topic 4 , we will very preliminarily consider bio-cultural models of the history of human society and cultural models restricted to the western history, which intersect via special place assigned to human cooperation, in all those models. They are, then, suited for these times of civilizational/environmental crisis. We will start with a sketch of the Nowak's bio-cultural pattern (Nowak, 2006; Nowak, 2010; Nowak, 2011; Nowak, 2012; Nowak, 2012; Tamita and Taubes, 2013) embracing - supported in mathematical models - the totality of human civilization history; such a pattern involves alternative cooperative and selfish cycles, cooperative cycles being intrinsically unstable. Next, we will sketch the Wilson`s bio-cultural pattern (Wilson, 2012) which also embraces the set of the whole human history. This last model articulates: i) a multilevel process embracing individual and group selections (this last selection explains evolutionary cooperation effects), where neither individual nor group selections must not be, isolated, fully predominant; ii) each individual within a growing complexity network of the urban-industrial civilization, clashing with our millenary instincts toward small groups arrangements. We will argue that model features like (ii) could be improved if one attaches superior limits of complexity to them through the help of two systemic "theories".

Closing topic 4, we argue that bio-cultural models (of human history) like the ones of Nowak and Wilson intersect certain history models - supposedly only cultural ones - of human sciences, particularly as regard human cooperation: particularly, Weber-Alberoni model (Alberoni, 1989). Max Weber, around 1918 (Alberoni, 1989), claimed that he has detected local, transient, unstable and purely cooperative western religious experiences that sometimes may even lead to civilizational jumps: that was the case of Christianity origins. It will be emphasized that Alberoni (1989) has extended this same weberian religious pattern to the great and contemporary non-religious political revolutions and has associated such experiences to a Prigogine-like dissipative model (Prigogine, 1984; Prigogine, 1984). Alberoni also has stressed the clear non-capitalist side of such purely cooperative experiences. We will claim that this weber-alberonian model - talking into account the last phrase - is closely related to our SCTC geometric model, explained in topic 2 and employed in topics 3 and 4. 


\section{Sustainable Complex Triangular Cells (SCTC): Competition and Cooperation}

The SCTC model, introduced by Sthel and Tostes (2012) is based on the use of a simple geometric shape, scalene triangle (Fig. 1), to represent the inseparability between three important topical issues: energy, environment and economy (3E) presenting a complex and systemic view of human society. A point placed in the geometric center of each triangle represents an individual of any modern society (competition). Finally, the area of the triangle corresponds to the "ecological footprint" of the individual (carbon footprint).There are three arrows that start from the center of each edge of the triangle, converging toward its midpoint, the individual. The direction of the arrows represents a highly individualized consumption of natural resources and fossil energy source. The neoliberal policies stimulate a huge consume and a cultural pattern where the competition and individualism are valued. The vertices of the triangle (3E) are progressively spaced and, consequently, there is an increase in the asymmetry of those three concepts, thereby creating a situation of increasing environmental unsustainability.

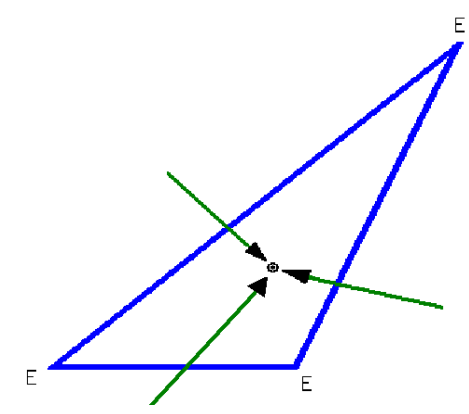

Figure 1. Representation of an individual in the present-day, scalene triangle (competition). (Sthel and Tostes, 2012)

Among individuals in contemporary society, there is a per capita consumption of highly differentiated natural resources, which leads to a situation of extreme social complexity (Arthur, 1998; Luhmann, 1995; Levin, 1999). The absence of inseparability of the three concepts (energy, economy and environment) can be observed as they feedback each other, thus forming cyclic bonds (Sthel et al., 2013), where there is an intense exchange of matter and energy with the environment, characteristic of an open, complex and dynamic system (Kaufmann, 1993; Watkins and Mervyn, 2008; de Vasconcellos, 2002). A plethora of scalene triangles can represent the people of today society, with great variability in their areas, associated with social, economic and cultural issues of any individual in this society. Thus, the scalene triangular complex cell patterns represent a chaotic description of recovery of the individual and the competitiveness of the current prevailing economic model.

To represent more sustainable society-environment relations, a new triangle was proposed, the equilateral triangle, where relations between $3 \mathrm{E}$ would be more symmetrical (balanced). However, even with the transformation to an equilateral triangle, the arrows remain pointed to the individual, still indicating a large individualized consumption of natural resources. Thus, a major challenge for humanity would be to reverse the direction of these arrows, accepting a new cultural pattern of cooperation (Sthel and Tostes, 2012). In this new representation, the individual would use and accept collective solutions (sharing of natural resources) to address environmental issues. By sharing resources, the total resource consumption would be reduced.

When the arrows are reversed, it will be possible to couple the equilateral triangles (individuals) in order to form a pattern of regular hexagon type (Fig. 2). In this pattern, relations among members of the ecological community are not linear, involving multiple feedback loops. To strengthen community means to strengthen relations between individuals (cooperation). The new structure represented by the regular hexagon can be coupled, into a network, to other similar hexagonal structures, representing a large social cooperative network. A model of a sustainable social system that continues to exchange energy and matter with their environment is generated. In other words, this system is structurally open, but has a close growth pattern in the network. From the chaotic structure of the current model of asymmetric individualized scalene triangles, order is generated, through non-deterministic change in the cultural paradigm, leading to the emergence of a new self-organizing system (Kaufmann, 1993; Watkins and Mervyn, 2008; de Vasconcellos, 2002). 


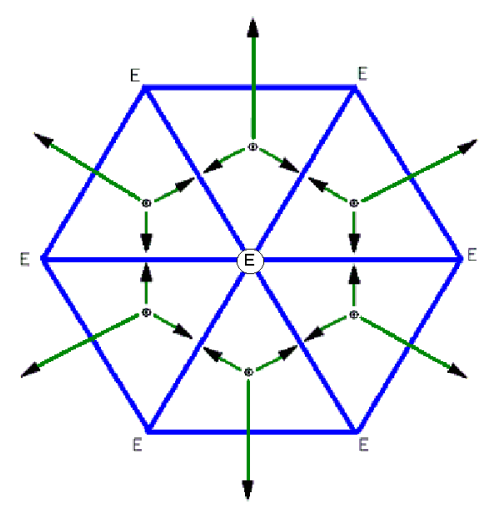

Figure 2. Regular hexagonal structure: Sharing natural resources (cooperation). (Sthel and Tostes, 2012; Sthel et al., 2013)

In fact, the representation of the arrows out indicates the ability to maintain the interdependence between individuals that make up the set of regular hexagons, thus forming a network structure, which share resources and environmental services in a sustainable cooperative manner. In this model, we consider that the sharing of natural resources leads to a reduction of the individual's carbon footprint of this regular hexagon community; i.e. it leads to a reduction of the total area of the hexagon, that is less than the sum of their individual areas of equilateral triangles. As examples, we can quote the use of renewable energy, collective transport, energy efficiency programs, recycling programs, collaborative consumption, vehicle sharing, efficient use of water resources, and sustainable use of land and a rigid controlling of greenhouse gases emission.

\section{Environmental Capitalism Limits and Geometric Model of Sustainability}

In two previous studies (Sthel and Tostes, 2012; Sthel et al., 2013) the capitalist system and its boundaries were preliminary located within our systemic geometric model of sustainability.

In the first article (Sthel and Tostes, 2012), relative to the current "scalene" stage of capitalism, the authors claimed that: "The actual society is multilayered, with enormous economic inequality that tends to be strongly articulated with the planetary capitalist matrix". There could be a possible transition within the capitalism (here represented by interacting triangular individuals) from a scalene triangle (arrows pointing inward) to the capitalism represented by an equilateral triangle (arrows still pointing inward). The latter triangle represents an economic model that (the great capitalist nations) are trying to build up for a supposed optimal (capitalist) economy that is seemingly "equilibrated", but rigorously speaking that model is still untenable (in environmental terms).

Since the crisis began in 2008, a fraction of American economists, on behalf of capitalism, has - speaking in a simplified fashion - been split in two deeply opposed sides: at one side, authors presenting very lyric analysis about today capitalism (Pinker, 2012); at the other, authors deeply critical to capitalism. These last critical voices are, in general, catastrophic and therefore tell, more or less explicitly, about the general limits of capitalism. We have selected three among these voices.

Firstly, the French economist T. Piketty (2014), whose book, "Capital in the XXI century" has had enormous repercussion in USA in 2014. He claims that there is a growing social inequality gap during the last third or fourth decades, particularly in the advanced capitalism countries. Such a gap would - in the ultimate instance be, following him, due to a "central contradiction of capitalism", a law the he derives asserting that the rate of return on capital always exceeds the rate of growth of income (the side more akin to the labor factor) and that could lead the economic system to an "infinite spiral of inequality". Piketty points to a fiscal rational solution: an international capitalist regulation through a world tax enhancement for the "riches", but he has left opened the crucial question of present political conditions for reaching such an economical solution in the foreseeing future. Second, the American mathematician J. Casti (2012), member of the Santa Fe Institute and of Rand Corporation, who applies the "science of complexity" - in its cybernetic ramification - to social systems within the mainstream of the new system scientific thought (T2) (de Vasconcellos, 2002), as opposed to the ancient Newton-Cartesian (T1) alternative (de Vasconcellos, 2002). To understanding Castis` arguments about present capitalism and their associated contradictions, we need, before, to master his central concept of complexity. An excerpt of this author dealing with the enormous and growing inequality (remember Piketty) gaps (the famous 
USA " $1 \%$ x 99\%" gap) in the last three decades, will help us understanding the concept of "complexity gap":

"In a scathing attack on the growing income inequality in America (...). Stieglitz (2011) made the following statement in 2011: the top 1 percent have the best houses, the best educations, the best doctors and the best lifestyles, but there is one thing that money doesn't seem to have bought: an understanding that their fate is bound up with how the other $99 \%$ live. From this observation, one might draw the inference that the number of lifestyles choices available, ranging from houses, doctors, travel and education serves as a reasonable measure of the complexity level of a person's life. Put compactly, the more choices you have, the more complex is your life. (...). In other words, the rich have many degrees of freedom (i.e., choice of action). What I actually choose to do doesn't affect the complexity level of my life at all. To make it complex, it's enough just to have choices available; and for a better or for worse, to large extent it's money that buys those choices in our world [our emphasis].

Following immediately this above quotation, Casti claims that if this state of affairs is maintained without a human rational intervention, it will - very probably - lead American capitalism to an upper limit for the enlargement of that inequality gap and to a consequent abrupt and spontaneous reduction of that same gap:

With this concept of complexity in mind, there's not a shadow of doubt that USA is experiencing a societal complexity imbalance that's grown exponentially over the past few decades (...) a huge awakening is on tap that will result in a rapid and painful X-event ["extreme event"] to close this gap. (...) I've painted a dire picture of how human-created complexity fits the first Marxian view of history to a tee. This is especially sad since at the same time we are living in the most technologically advanced society ever known to humankind. Yet we continue to sow the seeds of our own destruction, seeds that are for the first time in history able to develop in the destruction of our entire species" [our emphasis].

The recent and monumental crisis of 2008-2009 was also, according to Casti, a spontaneous result ("extreme event") emerging from a growing complexity gap between the supposedly regulator system (the State, principally) and the supposed regulated system (the financial system). It was the financial system, in the last three decades, that has becoming increasingly complex (more and more interconnected degrees of freedom) in relation to its supposed "regulator", the State. It was increasingly complex (even to its own creators) towards extracting the highest possible profit of increasingly financial transactions. However Casti questions: "how useful are those profits when they cause the system itself to collapse? Thirdly, the American economist N. Roubini that predicted in 2006 - in its general lines - the economic disaster of 2008. After this famous prediction, Roubini, in an interview with the Wall Street Journal in 2011 (Roubini, 2011), lent to Marx, himself, what might be called a "limiting contradiction of capitalism" to criticize (In a fair correspondence with Piketty) the increasing U.S. income concentration, even during the financial crisis, exploding in USA in 2008 and extended to the EU from 2010 on.

K. Marx had it right. At some point, capitalism can destroy itself. You cannot keep on shifting income from labor to capital without having an excess capacity and a lack of aggregate demand. That's what has happened. We thought that markets worked. They are not working. The individual can be rational. The firm, to survive and thrive, can push labor costs more and more down, but labor costs are someone else's income and consumption. That's why it's a [irrational] self-destructive process [our emphasis].

In an article in the same year, he essentially reiterates the same viewpoint (Roubini, 2011):

So Karl Marx, it seems, was partly right in arguing that globalization, financial intermediation run amok and redistribution of income and wealth from labor to capital could lead capitalism to self-destruct [...]. Firms are cutting jobs because there is not enough final demand. But cutting jobs reduces labor income, increases inequality and reduces final demand [our emphasis].

As a possible solution for stopping that limiting self-destructive tension of capitalism, Roubini advises a set of actions centered in the following axis (Roubini, 2011): "return to the right balance between markets and provision of public goods." Only one of the actions suggested by him suffices, for the purposes of the present work, to be mentioned here: a "stricter supervision and regulation of a financial system run amok: breaking up too-big-to-fail banks and of oligopolistic trusts". There comes again, just like in Piketty, the proposed and rational "regulatory healing" and again it is missing to be given the present political conditions for implementing such a "healing", provided - in ultimate instance - by the State. The present political/economical state of the art of advanced capitalist countries - through the theoretical systemic lenses of Casti - makes highly improbable any rational and efficient State regulatory proposal; in fact, the gap between the high complexity of financial system level and the low complexity of regulatory agencies level is growing again. It seems that a new crisis [extreme event] is being "attracted" by this growing complexity gap. 
In fact, the representation of the arrows out indicates the ability to maintain the interdependence between individuals that make up the set of regular hexagons, thus forming a network structure, which share resources and environmental services in a sustainable cooperative manner. In this model, we consider that the sharing of natural resources leads to a reduction of the individual's carbon footprint of this regular hexagon community; i.e. it leads to a reduction of the total area of the hexagon, that is less than the sum of their individual areas of equilateral triangles. As examples, we can quote the use of renewable energy, collective transport, energy efficiency programs, recycling programs, collaborative consumption, vehicle sharing, efficient use of water resources, and sustainable use of land and a rigid controlling of greenhouse gases emission.

\subsection{Scalene Triangle EEE: Accelerated "Scalenization" Process of the Capitalist System for the Last 80 Years Causing Environmental Effects and the Development of an Environmental Limit for Such System}

Before 1800, civilization experienced a long geo-environmental era of stability, the Holocene, when the Earth was able to absorb more or less smoothly external and internal disturbances. A new period, the Anthropocene (Crutzen and Stoermer, 2000; Crutzen, 2002; Zalasiewicz, 2010), has emerged since the Industrial Revolution and one of its main characteristics is the centrality of human actions on global environmental changes. But one of these actions, in particular, has spectacularly accelerated the world environmental problems (Fernandes, 2014). It was specifically a capitalist response to the 1929 crisis that was a decisive anthropic detonator of climate changes and other environmental impacts: the planned obsolescence or accelerated disposal of production (Dias, 2009), among other deleterious effects to the environment, has been accelerating the brutal consumption of natural resources, pollution, global warming etc. So, we start here to a first application of our SCTC geometric model. The deleterious environmental side of the process - extended about eighty years - of those responses to the 29 crisis may be modeled as an accelerated "scalenization" or distorting process of the sides of each EEE triangle (each individual). This strong and unilateral process of emphasis in vertex E (Economy) may be geometrically represented as a strong pulling of this vertex. But if that above mentioned response to that 1929 crisis helped there the capitalism to get out of an enormous cyclical crisis, now, that same response, is tending to send it to one of its necessary or insurmountable limit. One is referring to the environmental limit provoked, in part, by the set of nine great global environmental problems outlined in ref. (Rockstrom, 2009). If the capitalist economic system had decided to internalize, up to around 2050, the costs of environmental damage (generated and/or extended by the system itself) for all nine global environmental problems (which are interconnected!) (Rockstrom, 2009), this would severely affect the profit rate, one of the pillars of economic stability of the capitalist system. Moreover, the system inertia to confront environmental problems may have much more disastrous economic effects on that same stability of the capitalist production system even if only one, repeating, of those nine problems - global warming - is being presently considered (Stern, 2006).

\subsection{Equilateral Triangle EEE (With Arrows out): Evanescent Local Processes of Cooperative "Equilateralization" Mixed with Competitive Capitalist Elements, on the Last 40 Years}

Against the capitalist universal "scalenization", during the last 40 years, some brief, unstable and evanescent processes of cooperative "equilaterization" (arrows outward) occurred. Such "equilateralization" beyond capitalism, appeared mixed in some degree or extent, with competitive capitalist ingredients. These cooperative counter-tendencies existed jammed - briefly and in a contradictory fashion - inside the competitive "scalenizated" capitalist global matrix during the last 40 years. The instability and evanescence of such cooperative "islands" within the systemic capitalist "ocean" certainly prevents them to become stable hexagons, which would signal more effectively post-capitalist societies and therefore sustainable in environmental terms. In terms of our SCTC model, the incipient non-capitalist cooperative equilateral triangles (with arrows out) generated in these "islands" are soon or later distorted back to its usual and predominant scalene competitive configuration.

A first example of those evanescent "islands" is related to the emergence of the concept of eco-development in the 1970s, mainly associated with I. Sachs (1991), still within the templates of the Welfare State era. This author seeks to articulate ecological / biological diversity and cultural diversity, refusing to developmental solutions supposedly respecting ecosystems - allegedly "universal solutions" and to corresponding generalized formulas. The element "cooperation" was precisely present in that strong cultural appeal of Sachs, but it is rapidly "forgotten" later in the new neoliberal times and its alternative concept of sustainable development in the 1980s. Moreover, in a contradictory fashion, Sachs (2009) recommends that the national, state and local governments should adopt the model (competitive element) of large enterprise, though not by the appeal to the simple dynamics of market forces but also involving planning (again in line with the Welfare State).

Within that same cooperative side of Sachs' proposal, that tries to join ecology and culture through cooperation, 
in the present times we can also mention the advanced models of systemic complexity by Ostrom (2009): the simple socio-ecological systems (SES) once again mixed to elements of the current capitalist economy and, then, very probably condemned to short lifetimes.

\section{Bio-Cultural/Cultural Models of Cooperation for Times of Civilizational/Environmental Crises}

The biologist M. Nowak (Nowak, 2006; Nowak, 2010; Nowak, 2011; Nowak, 2012; Nowak, 2012) writes that in the planetary environmental history in course, our chances of saving human life seems to be small, once we need to conserve natural resources that are quickly shrinking in a world with a growing consuming population of technologically advanced products. His argument is correct, once the current economic model prioritizes individualism and competition (Andrews, 2013; Klitgaard, 2013; Pellizzoni, 2011), instead of the Nowak`s postulated cooperation. More specifically, Nowak exhibits a bio-cultural pattern - based upon mathematical models - which would cross the total human history (Nowak, 2012):

Evolutionary simulations indicate that cooperation is intrinsically unstable; periods of cooperative prosperity inevitably give way to defective doom. And yet the altruistic spirit always seems to rebuild itself; our moral compasses somehow realign. Cycles of cooperation and defection are visible in the ups and downs of human history, the oscillations of political and financial systems.

So, unstable cycles of cooperative prosperity tend to give place to - relatively - much more stable cycles of destructive defection (competition, not cooperation, prevailing, as it is the example of the capitalist world-system). However, in the present advanced stage of the environmental crisis, the fearful climate changes no longer seem capable of being faced by politic-economical - traditional and safe - solutions unless governments and great social movements adopt strategies like one known as "dampening cultural mechanism" (Sthel and Tostes, 2012), a cooperative scheme already utilized by our so called "pre-historical" ancestors.

The biologist E. Wilson (2012), in turn, presents another bio-cultural pattern crossing also the total human history. Following Wilson (2012), the biological evolution of species, principally from hominid tree on, would have as its driven "force" a multi-level selection, composed of an individual selection and a group selection, acting conjointly over the same individual, mostly one part against the other. According to Wilson:

Individual selection is the result of competition for survival and reproduction among members of the same group. It shapes instincts in each member that are fundamentally selfish with reference to other members. In contrast, group selection consists of competition between societies, through both direct conflict and differential competence in exploiting the environment. Group selection shapes instincts that tend to make individuals altruistic toward one another (but not toward members of other groups) [...]. Nevertheless, an iron rule exists in genetic social evolution. It is that selfish individuals beat altruistic individuals, while groups of altruists beat groups of selfish individuals. The victory can never be complete; the balance of selection pressures cannot move to either extreme. If individual selection were to dominate, societies would dissolve. If group selection were to dominate, human groups would come to resemble ant colonies. [emphasis added]

Within few pages ahead, Wilson concludes:

In addition to the origin of instinctive empathy, group selection can at least in part be invoked to explain cooperation, an even more important trait of human nature.

In this qualitative bio-cultural model it is presented a kind of contingent "selection window" (through the "equilibrium of selection pressures"), which keeps on, till now, sustaining and equilibrating itself for the hominids between the two above mentioned "pure" and "undesirable" extremes. It is to be stressed how this Wilson`s qualitative bio-cultural pattern modulates the Nowak`s mathematical bio-cultural pattern: the two kinds of alternative cycles of Nowak's pattern should not be driven toward its respective extremes of "pure" selfishness or cooperation. If this were the case, hominid evolution would be severely menaced of deviations as regard its multi-secular actual trajectory leading to Homo sapiens.

The Wilson's model still presents another side: it articulates each individual with a growing complexity network (Wilson, 2012):

Each individual is linked to a network of other group members. Its own survival and reproductive capacity are dependent in part on its interaction with other in the network. [...] Throughout prehistory, as humanity evolved its cognitive prowess, the network of each individual was almost identical to that of the group to which he belonged. [...] With the emergence of villages and then chief downs in the Neolithic period around 10,000 years ago, the nature of the networks changed dramatically. [...] His social existence became far less stable than the world of hunter-gatherers. In modern industrialized 
countries, networks grew to a complexity that has proved bewildering to the Paleolithic mind we inherited. Our instincts still desire the tiny, united band-networks that prevailed during the hundreds of millennia proceeding the dawn of history. Our instincts remain unprepared for civilization. [emphasis added]

In this Wilson's model arises a growing detachment between a growing urban and complex civilization and our evolutionary inherited tendency, along thousands of years toward strongly united small population webs. Then, the famous ecological label, "small is beautiful", would be, nothing more, nothing less, than an expression of that evolutionary tendency.

We have selected a last side - a conjecture - of Wilson's model (Wilson, 2012):

Additional studies suggest [...] that [socioeconomic] leveling in beneficial even for the most advanced modern societies. Those that do best for their citizens in quality of life, from education and medical care to crime control and collective self-esteem, also have the lowest income differential between the wealthiest and poorest citizens. [emphasis added]

Synthetically, the Wilson's bio-cultural model exhibits the following features that we think as more relevant (for our following analysis):

W1) the multilevel selection constituted from two kinds of selection: individual and group selection; here, right from the beginning, the importance of cooperation is emphasized in bio-cultural terms starting from group selection;

W2) a "selection window", favorable as regard hominids evolution;

W3) each individual is articulated to a (group) network of growing complexity, toward industrial civilization, in the opposite side of our instincts which "desire" small group networks;

W4) One may conjecture that the way toward national socioeconomic leveling is more worthwhile even for the already most advanced human societies.

Let us remember the (growing) "complexity" concept employed by Wilson: a system with many components and exhibiting enhancement in number and diversity of connections among those components (Wilson, 2012). The issues W3 and W4 would become more sophisticated if we attach them upper limits of complexity. We could do it through two distinct systemic theories (i.e., both traversed by the same systemic scientific thought, T2, already seen above). One of those theories is the "complexity science" of Prigogine (Prigogine, 1984; Prigogine, 1984). He argues that systemic complexity growth exhibits upper limits. Beyond these limits, the system (pre-biotic, biological or bio-cultural) tends to a high instability (Prigogine, 1984):

The question of the limits of complexity has often been raised. Indeed, the more complex a system is, the more numerous are the types of fluctuations that threaten its stability. How then, it has been asked, can system as complex as ecological or human organizations possibly exist? How do they manage to avoid permanent chaos? The stabilizing effect of communication, of diffusion processes, could be a partial answer to these questions. In complex systems, where species and individuals interact in many different ways, diffusion and communication among various parts of the system are likely to be efficient. There is competition between stabilization through communication and instability through fluctuations. The outcome of that competition determines the threshold of stability.

This Prigogine's mechanism could be attached to the W3 item above. On the other hand, Casti (2012), employing a cybernetic simple model [see topic 3], claims that for a given pattern of a growing systemic complexity, there is also a growing tendency that such a system becomes more and more instable and, possibly, reaches a critical point - an extreme event ("X-event") - which will diminish, drastically and spontaneously, that system complexity. Once again, we have a mechanism that could be employed in W3. Now, regarding item W4, it can be employed a variant of the same cybernetic theory utilized by Casti (see topic 3). He claims that "growing gaps of complexity" (in the present case of W4 there is a gap between maximum and minimum national incomes) could also lead to a dangerous enhancement of systemic instability, which may lead to a drastic and spontaneous shrinking of those gaps.

For certain porpoises of the present work we may consider Nowak and Wilson models as just one fused model.

The bio-cultural models of human history of Nowak and Wilson possess intersections with models of great inflexions in the western history - supposedly only "cultural" models - of human sciences; particularly, regarding human elements of cooperation. Firstly, we return to the beginning of XX century: Max Weber (Alberoni, 1989) in 1918, in his text "Economy and Society", has detected local experiences in certain western 
religious phenomena that seem to be strong and purely cooperatives; he has labeled such experiences as "nascent states". In some rare occasions, under specific historical (at least in western world) conditions, such experiences may lead to deep social inflexions, even to a civilization jump (Alberoni, 1989), starting from a small "island community" (or from an "archipelago" of such small "islands"), inside a much greater "oceanic social system". Such a small "island" then is very quickly amplified through that "ocean". One of such remarkable experiences was the very rapid spreading of Christendom through the roman imperium. Such a kind of experience is strongly and internally characterized by a transient and a non institutional process: so, it possesses an intrinsic instability. However, it may be sufficiently stable so as to provoking the mentioned kind of civilizational jump toward new stable institutions.

The Italian sociologist F. Alberoni (1989) has extended that same Weber's "nascent state" pattern to the great secular contemporary political revolutions, which are much better documented as regard analogous experiences of I Century of Christian era. The intersections with Wilson model are evident in space and time: the extreme cooperation of "nascent states" of Weber-Alberoni is possible only for small groups (the environmentalists once more "rediscover the wheel", a "wheel" which comes, following Wilson, from distant times preceding agriculture civilization: "small is beautiful"). Such an extreme cooperation is also only carried out through relatively small time intervals: repeating, it is intrinsically instable.

Finally, Alberoni (1989) associates such experiences of "nascent states" with a process that generates disorder. Once a certain disorder limit is surpassed, it is no longer possible a reversion to the preceding institutional order:

"it happens just like in the dissipative systems, studied by Prigogine. All the [preceding institutional] structure enters into a crisis and may suffer a deep reformulation with a new order" (Alberoni, 1989). That's the "order out of chaos" as described in the "science of complexity" of Prigogine (Prigogine, 1984, Prigogine, 1984). Alberoni concludes that the most general condition for the emergence of such transient "super-cooperator" communities of "nascent state" are those strong crises which no longer allow for solutions (even partially) based upon competition, normally acceptable in stable institutional structures.

The clear non-capitalist character of those extremely cooperative experiences of "nascent states" can be further clarified from the Weber-Alberoni viewpoint. Alberoni (1989) lists a set of common characteristics of those "states", partially extracted from Weber: i) complete absence of any economic accountancy, i.e. absence of any State tax coercion; in ultimate stance, absence of any State coercion; ii) total sharing of all community goods or, in other words, the distributive practice: "each according to his needs"; iii) fully participative democracy. As these super-cooperative experiences are dynamical ones, today - in times of environmental crisis - they should incorporate, for instance: iv) the necessity of a new and deeply post-Cartesian relationship man-nature or, perhaps more precisely, man-environment.

Synthetically, first, we have articulated in the present topic 4 - still in a very preliminary fashion - the human history bio-cultural models of Nowak and Wilson, highlighting a cooperative landmark, in one side, and the purely cooperative Weber-Alberoni model for certain great inflexions in the western history, supposedly only a cultural model, in the other side. Second, we have associated - again in a preliminary fashion - the two kinds of models (Nowak-Wilson and Weber-Alberoni) with the new scientific systemic thinking, T2, through the qualitative employment of two systemic theories: the "complexity science" of Prigogine and one of a set of cybernetic theories, that one employed by Casti. Third, and most important for the porpoises of the present work, the Weber-Alberoni model may be related to our SCTC geometric model - which has been employed in topic 3 because in the case of equilateral triangle (arrows out) of SCTC model and as also the case of "nascent state" of Weber-Alberoni model, we have cooperation without any trace of competition.

\section{Conclusion}

We have employed in the present work different - all of them being qualitative and simple - models of human history and human society. (1) They run from extremely abstract models (the SCTC geometric model and its place for an individual represented by a triangle) to more "flesh and blood" models (like the Weber-Alberoni model). (2) They should all be included in the kind of "systemic models"; more precisely, they are traversed by the new scientific thinking (T2). (3) They also, all, include the central concept of "non-capitalist cooperation, in times of civilizational and environmental crisis" (see the title of the present work). (4) Particularly, at least two of the models analyzed here, deal with cooperation without any trace of competition; in the specific case of Weber-Alberoni "nascent state" model, it is claimed that there is the support of several, but instable, remarkable historical experiences of rapid amplification of that small "state".

Let us now close the first paragraph of the present work. Many people, still dispersed or organized in very small

(!) clusters, are now searching for a new civilization pattern, alternative to capitalism and beyond western 
political-economic hegemony, based upon a new sustainable/cooperative global, but also multi-civilization, project and - presently being built up - an "immaterial" new systemic scientific thinking (T2), adjusted to that project. No longer the old Newton-Cartesian thinking (T1), adjusted to the enlightenment project.

\section{Acknowledgments}

The authors would like to thank the Brazilian agencies CNPq, FAPERJ and CAPES for the financial support.

\section{References}

Alberoni, F. G. (1989). Garzanti Editore: Milano, Italia.

Andrews, J., \& Davidson, B. J. (2013). Cell-Gazing Into the Future: What Genes, Homo heidelbergensis and Punishment tell Us about Our Adaptive Capacity. Sustainability, 5, 560-569. https://doi.org/10.3390/su5020560

Arthur, W. B. (1998). Complexity and the economy. Science, 284, 2.

Balmaseda, M. A., Trenberth, K. E., \& Källén, E. (2013). Distinctive climate signals in reanalysis of global ocean heat content. Geophysical Research, 40, 1754-1759. https://doi.org/10.1002/grl.50382

Casti, J. L. (2012). X-events: the collapse of everything. NY: Harper \& Collins.

Chakravarty, S., Chikka, A., Coninck, H., Pacala, S., Socolow, R., \& Tavoni, M. (2009). Sharing global $\mathrm{CO}_{2}$ emission reductions among one billion high emitters. Proc. Natl. Acad. Sci., 106, 11884-11888. https://doi.org/10.1073/pnas.0905232106

Cox, P. M., Pearson, D., Booth, B. B., Friedlingstein, P., Huntingford, C., Jones, C. D., \& Luke, C. M. (2013). Sensitivity of Tropical Carbon to Climate Change Constrained by Carbon Dioxide Variability. Nature, 494, 341-344. https://doi.org/10.1038/nature11882

Crutzen, P. J. (2002). Geology of mankind. Nature, 415, 23. https://doi.org/10.1038/415023a

Crutzen, P. J., \& Stoermer, E. F. (2000). The Anthropocene. IGBP Newsletter, 41, 17-18.

de Vasconcellos, M. J. E. (2002). Pensamento sistêmico: o novo paradigma da ciência. SP: Papirus.

Dias, G. V. (2009). Capital, and environmental complexity: A study of the environmental crisis of the capitalist system (1930-2013). Máster Dissertation, Postgraduate Pro- gram in Environmental Science, UFF, Brazil.

Ding, Q., Wallace, J. M., Battist, D. S., Steig, E. S., Gallant, A. J. E., Kim, H., \& Geng, L. (2014). Tropical forcing of the recent rapid Arctic warming in northeastern. Canada and Greenland, Nature, 509, 209-212. https://doi.org/10.1038/nature13260

Fernandes, F. M. et al. (2014). A perigosa deterioração de ecossistemas. Sci. Am., 140, 70-75.

Flynn, K., Blackford, J. C., Baird, M. E., Raven, J. A., Clark, D. R., Beardall, J., ... Wheeler, G. L. (2012). Changes in $\mathrm{pH}$ at the exterior surface of plancton with ocean acidification. Nat. Clim. Change, 2, 510-513. https://doi.org/10.1038/nclimate1696

Hansen, J., Sato, M., \& Ruedy, R. (2012). Percetion of climate change. Proc. Natl. Acad. Sci., 109, 2415-2423. https://doi.org/10.1073/pnas.1205276109

Heath, Y., \& Gifford, R. (2006). Free-Market Ideology and Environmental Degradation: The Case of Belief in Global Climate Change. Environmental and Behavior, 38(1), 48-71. https://doi.org/10.1177/0013916505277998

IPCC. (2007). Climate Change 2007; The Physical Science Basis; Report of Working Group I; Cambridge University Press: Cambridge, UK.

Kaufmann, S. A. (1993). Origins of order. Oxford University Press.

Klitgaard, K. (2013). Heterodox political economy and the degrowth perspective. Sustainability, 5, 276-297. https://doi.org/10.3390/su5010276

Lenoir, J., Gégout, J. C., Marquet, P. A., Ruffray, P., \& Brisse, H. (2008). A significant upward shift in plant species optimum elevation during the 20th century. Science, 320, 1768- 1771. https://doi.org/10.1126/science.1156831

Levin, S. A. (1999). Fragile Dominion: Complexity and the commons. Perseus Books.

Luhmann, N. (1995). Social System. Stanford University Press.

Novak, M. A. (2011). Super Cooperators: Altruism, Evolution and Why we Need Each Other to Succeed. Simon 
\& Schuster. Inc. New York, NY.

Nowak, M. A. (2006). Five Rules for the Evolution of Cooperation. Science, 314, 1560-1563. https://doi.org/10.1126/science. 1133755

Nowak, M. A. (2010). Tarnita, C.E.; Wilson, E.O. The evolution of eusociality. Nature, 466, 1057-1062. https://doi.org/10.1038/nature09205

Nowak, M. A. (2012). Evolving Cooperation. J. Theor. Biol., 299, 1-8. https://doi.org/10.1016/j.jtbi.2012.01.014

Nowak, M. A. (2012, June). Why We Help: The Evolution of Cooperation. Scientific American. https://doi.org/10.1038/scientificamericanhuman1112-92

Ostrom, E. (2009). A general framework for analyzing sustainability of social-ecological systems. Science, 325,419-422. https://doi.org/10.1126/science. 1172133

Palmer, T. (2014). Record-breaking winters and global climate change. Science, 344, 803-804. https://doi.org/10.1126/science. 1255147

Pellizzoni, L. (2011). Governing through disorder: Neoliberal environmental governance and social theory. Global Environmental Change, 21, 795-803. https://doi.org/10.1016/j.gloenvcha.2011.03.014

Piketty, T. (2014). Capital in the Tewnty-first century. Harvard U.P., N.Y. https://doi.org/10.4159/9780674369542

Pinker, S. (2012). The better angels of our nature; why violence has declined. NY: Penguin Books.

Prigogine, I., \& Stengers, E. (1984). A nova aliança. Brasília: UNB.

Prigogine, I., \& Stengers, I. (1984). Order out of chaos: Man's new dialogue with nature. Bantam Books, New York.

Ramsay, H. (2014). Shifting storms. Nature, 509, 290-291. https://doi.org/10.1038/509290a

Randerson, J. T. (2013). Global warning and tropical carbon. Nature, 494, 319-320. https://doi.org/10.1038/nature11949

Rockstrom, J. et al. (2009). A Safe Operating Space for Humanity. Nature, 461, 472-475. https://doi.org/10.1038/461472a

Rosenzweig, C. et al. (2008). Attributing physical and biological impacts to anthropogenic climate change. Nature, 453, 353-357. https://doi.org/10.1038/nature06937

Roubini, N. (2011, August, 15). Is capitalism doomed? Retrieved July, 2014, from http://www.economonitor.com/nouriel/2011/08/15/is-capitalism-doomed/

Roubini, N. K. (2011). Marx was right. Interview. Wall Streed Journal, August, 12.

Sachs, I. (1991). Ecodevelopment: grow without des-troying. Vértice, São Paulo.

Sachs, I. (2009). The energy of tomorrow. Carta Capital, 567, 54-57.

Slade, G. (2006). Made to break: technology and obsolescence in America. Harvard UP.

Solomon, S., Plattner, G., Knutti, R., \& Friedlingstein, P. (2009). Irreversible climate change due to carbon dioxide emissions. Proc. Natl. Acad. Sc., 106, 1704-1709. https://doi.org/10.1073/pnas.0812721106

Stern, N. (2006). Stern review: The economics of climate change, UK.

Sthel, M. S., \& Tostes, J. G. R. (2012). Sustainable Complex Triangular Cells: Case Study-Envira River Isolated Indians in Western Amazon. J. Sustain. Dev., 5, 92-104. https://doi.org/10.5539/jsd.v5n8p92

Sthel, M. S., Tostes, J. G. R., \& Tavares, J. R. (2013a). Current energy crisis and its economic and environmental consequences: intense human cooperation. Nat. Sci., 5, 244-252. https://doi.org/10.4236/ns.2013.52a036

Sthel, M. S., Tostes, J. G. R., \& Tavares, J. R. (2013b). Sustainable complex triangular cells for the evaluation of $\mathrm{CO}_{2}$ emissions by individuals instead of nations in a scenario for 2030. Sustainability, 5, 1944-1959. https://doi.org/10.3390/su5051944

Sthel, M. S., Tostes, J. G. R., \& Tavares, J. R. (2015). 21th COP and climate changes: will it go beyond dominating superficiality since 2008 COP's? J. Earth Sci. Climat. Change S3, 1-4.

Stiglitz, J. (2011, May). Of the 1\%, by the 1\%, for the 1\%. Vanity Fair.

Stocker, T. M. (2013). The Closing Door of Climate Targets. Science, 339, 280-282. https://doi.org/10.1126/science. 1232468 
Tarnita, C. E., Taubes, C. H., \& Nowak, M. A. (2013). Evolutionary construction by staying together and coming together. J. Theor. Biol., 320, 10-22. https://doi.org/10.1016/j.jtbi.2012.11.022

Tollefson J., \& Weiss, K. (2015). Nations adopt historic global climate accord. Nature, 528, 315-316. https://doi.org/10.1038/528315a

Watkins, N. W. (2008). Mervyn, Natural Complexity. Science, 30, 18.

Wilson, E. O. (2012). The Social Conquest of Earth. Liveright: New York, NY, USA.

Zalasiewicz, J. (2010). The New World of the Anthropocene, Environ. Sci. Technol, 44, 2228-2231. https://doi.org/10.1021/es903118j

\section{Copyrights}

Copyright for this article is retained by the author(s), with first publication rights granted to the journal.

This is an open-access article distributed under the terms and conditions of the Creative Commons Attribution license (http://creativecommons.org/licenses/by/4.0/). 